\title{
Patterns of recurrence after open partial horizontal laryngectomy types II and III: univariate and logistic regression analysis of risk factors
}

\author{
Patterns di recidiva dopo intervento di laringectomia parziale orizzontale tipo II \\ e III: analisi univariata e regressione logistica dei fattori di rischio
}

\section{E. CROSETTI ${ }^{1}$, A. BERTOLIN², G. MOLTENI ${ }^{3}$, I. BERTOTTO ${ }^{4}$, D. BALMATIVOLA ${ }^{5}$, M. CARRARO ${ }^{1}$, A.E. SPRIO ${ }^{6}$, G.N. BERTA ${ }^{6}$, L. PRESUTTI7, G. RIZZOTTO², G. SUCCO', 8 \\ ${ }^{1}$ Head and Neck Oncology Service, Candiolo Cancer Institute - FPO IRCCS, Candiolo (TO), Italy; ${ }^{2}$ Otolaryngology Service, Vittorio Veneto Hospital, Vittorio Veneto (TV) Italy; ${ }^{3}$ Department of Otolaryngology-Head and Neck Surgery, University Hospital of Verona, Italy; ${ }^{4}$ Radiology Service, Candiolo Cancer Institute - FPO IRCCS, Candiolo (TO), Italy; ${ }^{5}$ Pathology Service, Candiolo Cancer Institute - FPO IRCCS, Candiolo (TO), Italy; ${ }^{6}$ Department of Clinical and Biological Sciences, University of Turin, Italy; ${ }^{7}$ Otolaryngology Service, Head and Neck Dept., Policlinico Hospital, University of Modena, Italy; ${ }^{8}$ Oncology Dept. University of Turin, Italy}

\section{SUMMARY}

In choosing the best surgical treatment (total or partial laryngectomy) for patients affected by laryngeal squamous cell carcinoma (SCC), it is still necessary to identify a link between prognostic factors and oncological outcomes. A retrospective analysis of clinical outcomes of 819 patients affected by laryngeal cancer who underwent OPHL type II and III between 1995 to 2014 was carried out. Focusing on recurrence and its site (local, regional or distant), our cohort has been divided in two groups: patients showing recurrence $(\mathrm{n}=108)$ vs those without recurrence $(\mathrm{n}=711)$. Thirteen clinical-pathological parameters have been studied by univariate and multivariate analysis to identify possible correlations between recurrence and oncological outcomes (overall survival (OS), disease free survival (DFS), disease specific survival (DSS), laryngectomy free survival (LSF), laryngectomy free freedom (FFL). In multivariate analysis, we found 4 negative prognostic factors for recurrence: site of tumour ( $>$ supraglottic), cartilage invasion ( $>$ if present), perineural invasion ( $>$ if present) and type of OPHL ( $>$ in OPHL type III). The knowledge and detection of negative prognostic factors for the risk of recurrence (pN classification, cartilage involvement, perineural invasion, and thus the type of surgical treatment adopted) could increase the already well-established potentiality of OPHLs in treating cases with a safe indication after careful discussion in the tumour board.

KEY WORDS: Open partial horizontal laryngectomy • Supracricoid partial laryngectomy • Supratracheal partial laryngectomy • Recurrence $\bullet$ Laryngeal cancer $\bullet$ Multivariate analysis

\section{RIASSUNTO}

Nella scelta del trattamento chirurgico (laringectomia totale o parziale) in pazienti affetti da carcinoma laringeo, è ancora necessaria l'identificazione di una correlazione tra fattori prognostici e risultati oncologici. Una coorte multi-istituzionale di 819 pazienti affetti da carcinoma laringeo e sottoposti a laringectomia parziale orizzontale (OPHL) tipo II e tipo III dal 1995 al 2014 è stata suddivisa in base alla comparsa o meno di recidiva (108 vs 711) ed alla sede di ricomparsa di malattia (loco-regionale, locale, a distanza). Sono state analizzate, mediante analisi uni e multivariata, tredici variabili cliniche e istologiche nei due gruppi, in relazione agli esiti oncologici (OS, DFS, DSS, LSF, FFL). All'analisi multivariata quattro sono risultati i fattori determinanti rischio di recidiva: sede del tumore (maggiormente nei tumori sopraglottici), invasione cartilaginea (maggiormente se presente), invasione perineurale (maggiormente se presente) ed il tipo di OPHL (maggiormente in caso di OPHL tipo III). La conoscenza e la detezione dei fattori prognostici negativi per il rischio di recidiva (classificazione $\mathrm{pN}$, interessamento cartilagineo, invasione perineurale e quindi trattamento chirurgico adottato) potrebbero aumentare le già note potenzialità delle OPHL nel trattare casi con indicazione certa dopo attenta discussione collegiale.

PAROLE CHIAVE: Laringectomia parziale orizzontale $\bullet$ Laringectomia parziale sopracricoidea $\bullet$ Laringectomia parziale sopratracheale $\bullet$ Recidiva $\bullet$ Carcinoma laringeo $\bullet$ Analisi multivariata 


\section{Introduction}

Nowadays, surgery can be offered to patients affected by laryngeal cancer as a valuable method to preserve part of the larynx and its functions, avoiding the negative physical and psychosocial impact of permanent tracheostomy ${ }^{12}$. In the last decade, organ-sparing techniques have been developed and extensively used, with excellent results, as upfront treatment in early ${ }^{34}$ and in selected more advanced stages (cT3 and cT4) ${ }^{5}$. Different therapeutic options are now available for cT3 and cT4 larynx cancers ${ }^{67}$ but a dichotomy exists considering locally advanced tumours: is the lesion amenable to partial laryngectomy or to total laryngectomy? During multidisciplinary discussions about larynx cancer treatment, this is not a simple question.

Each time, the surgeon faces the decision to attempt conservative treatment or to address the patient to a safer up-front total laryngectomy. The choice of treatment to recommend can be difficult to understand, especially for young or less experienced surgeons. In fact, if two lesions are at the same stage and patients are free from contraindications related to general conditions, why are they selected for different treatments?

This is because a clear consensus is still lacking for what concerns simple and objective parameters that should be used in the selection of patients amenable to one or the other technique. Although staging of laryngeal cancer has been considered for a long period the criterion that better correlates with loco-regional control and patient survival, prognosis is a complex phenomenon arising from tumour and patient characteristics, molecular biology, genetics and environment ${ }^{89}$. However, the importance of each has not been unequivocally demonstrated. To complicate matters further, negative prognostic factors involved in recurrence onset are not established universally, but are important to discriminate the most suitable treatment for the patient.

The application of logistic regression models to retrospective studies allows detection and/or analysis of prognostic factors that are potentially useful to predict the main oncologic and functional outcomes. Furthermore, data emerging from large multi-institutional series of cases who were treated with the same protocols provide insights about the most controversial aspects in the treatment indications.

In this multi-institutional retrospective study, we analysed a large series of locally advanced laryngeal cancer patients treated by open partial horizontal laryngectomies (OPHL) spurred by a dual aim: a) the identification of novel prognostic factors correlating with disease recurrence; b) improvements for more correct use of OPHL as a single and up-front laryngeal cancer treatment, based on results of the previous point.

\section{Patients and methods}

\section{Patients}

The study was conducted retrospectively analysing medical records from 819 patients affected by laryngeal cancer who underwent OPHL between January 1995 and December 2014 in tertiary reference Italian hospitals: Hospital of Vittorio Veneto (Treviso), Martini Hospital (Turin), Candiolo Cancer Institute (Turin) and Policlinico Hospital (Modena). Patient characteristics, distribution according to the involved laryngeal sites, as well as their $\mathrm{pT}$ and pN categories (2009 TNM classification system) ${ }^{10}$, are reported in Table I.

Inclusion criteria were histological diagnosis of glottic or supraglottic laryngeal squamous cell carcinoma (LSCC), Karnofsky index ${ }^{11}$ higher than 80 and amenability to OPHL type II for advanced laryngeal cancers maintaining laryngeal functions ${ }^{12}$ and type III surgeries for glottic/ transglottic cancers extending to the cricoid or to extralaryngeal space ${ }^{11314}$.

Exclusion criteria were: a) purely supraglottic T3 tumour with limited extension to the pre-epiglottic space (and therefore amenable to OPHL type I or transoral laser microsurgery); b) lesions extended to base of tongue or pyriform sinus; c) lesions with major invasion of pre-epiglottic space involving the hyoid bone, involving the inter-arytenoid space, the posterior commissure and both arytenoid cartilages; d) large extralaryngeal spread of cancer involving thyroid gland, strap muscles, cervical skin, internal jugular vein or common carotid artery; e) lesions reaching the first tracheal ring; f) severe diabetes mellitus; g) severe chronic obstructive pulmonary disease; h) neurological problems impairing the ability to expectorate and/or swallow; and i) severe cardiac disease. The presence of clinically positive nodes $>\mathrm{cN} 1$ was not considered as an absolute contraindication. However, it should not represent a good indication for OPHL due to the probable need for post-operative radiotherapy (RT) ${ }^{15}$. One hundred and forty patients $(17.1 \%)$ had already been treated previously for laryngeal carcinoma by $\mathrm{CO}_{2}$ transoral laser surgery $(61 / 140 ; 43.6 \%)$, radiation therapy $(39 / 140 ; 27.9 \%)$, laser surgery and radiation therapy $(11 / 140 ; 7.8 \%)$, cordectomy $(21 / 140 ; 15.0 \%)$, open partial laryngectomy $(7 / 140 ; 5.0 \%)$, or chemotherapy $(1 / 140$; $0.7 \%)$.

Thirteen clinical-pathological parameters are studied as possible negative prognostic factors: previous treatments, 
Table I. Epidemiologic and clinical characteristics of patients treated by OPHL in the present series $(\mathrm{N}=819)$.

\begin{tabular}{|c|c|c|c|}
\hline & & \multicolumn{2}{|c|}{ No of patients (\%) } \\
\hline \multirow[t]{2}{*}{ Age } & Mean \pm standard deviation & \multicolumn{2}{|c|}{$60.2 \pm 9.4$} \\
\hline & Range & \multicolumn{2}{|c|}{$16-87$} \\
\hline \multirow[t]{2}{*}{ Gender } & Male & \multicolumn{2}{|c|}{755 (92.2\%) } \\
\hline & Female & \multicolumn{2}{|c|}{64 (7.8\%) } \\
\hline \multirow[t]{2}{*}{ Arytenoid mobility } & Normal & \multicolumn{2}{|c|}{581 (70.9\%) } \\
\hline & Impaired/fixed & \multicolumn{2}{|c|}{$238(29.1 \%)$} \\
\hline pTN (VII ed.) & & Glottic & Supraglottic \\
\hline \multirow[t]{3}{*}{ pT2 } & NO & $201(31.8 \%)$ & $22(11.8 \%)$ \\
\hline & N1 & $2(0.3 \%)$ & $4(2.2 \%)$ \\
\hline & N2 & $3(0.5 \%)$ & $4(2.2 \%)$ \\
\hline \multirow[t]{3}{*}{ pT3 } & NO & $291(46.0 \%)$ & $86(46.2 \%)$ \\
\hline & N1 & $13(2.1 \%)$ & $11(6.0 \%)$ \\
\hline & N2 & $13(2.1 \%)$ & $23(12.4 \%)$ \\
\hline \multirow[t]{3}{*}{ pT4 } & NO & $94(14.7 \%)$ & 27 (14.4\%) \\
\hline & N1 & $10(1.6 \%)$ & $4(2.2 \%)$ \\
\hline & N2 & $6(0.9 \%)$ & $5(2.6 \%)$ \\
\hline Total & & $633(77.3 \%)$ & $186(22.7 \%)$ \\
\hline
\end{tabular}

type of surgery, tumour site, $\mathrm{pT}$ subcategory, $\mathrm{pN}$ classification, grading, cartilage involvement, vascular invasion, perineural invasion, Delphian lymph node $\mathrm{pN}+$, extranodal extension (ENE), status of margins, adjuvant treatments (Table II). Age was not considered among these factors because elderly patients affected by laryngeal cancer can be treated as younger patients ${ }^{16}$.

\section{Surgical procedures}

Total laryngectomy and OPHL Type II are the most established solutions for intermediate-advanced stage laryngeal tumours affecting the glottis. OPHL Type III, instead, is amenable to glottic/transglottic tumours with subglottic extension reaching the cricoid and glottic/transglottic $\mathrm{T} 4 \mathrm{a}$ lesions with extralaryngeal progression through the caudal end of the thyroid cartilage and/or through the cricothyroid membrane ${ }^{1}$.

According to this, after informed consent had been obtained, all patients underwent OPHL types II-III ${ }^{17}$ with curative intent: type IIa $=159 / 819(19.4 \%)$, type $\mathrm{IIa}+\mathrm{ARY}=354 / 819(43.2 \%)$, type IIb $=46 / 819(5.6 \%)$, type IIb+ARY = 138/819 (16.9\%), type IIIa = $10(1.2 \%)$, type $\mathrm{IIIa}+\mathrm{CAU}=99 / 819(12.1 \%)$, type $\mathrm{IIIb}=5 / 819$ $(0.6 \%)$, type IIIb+CAU $=8 / 819(1.0 \%)$ (Table III).

Neck dissection (ND), graded according to the American Academy of Otolaryngology - Head and Neck Surgery Foundation classification ${ }^{18}$, was performed in 704 patients $(85.9 \%)$, and was unilateral in $606(86.1 \%)$ and bilateral in $98(13.9 \%)$ cases. ND was elective (ND lev- els II-IV) in $634 \mathrm{cN} 0(90.1 \%)$ and curative in $70 \mathrm{cN}>0$ $(9.9 \%)$ patients. Level VI or unilateral paratracheal lymph node clearance was added in $449(63.7 \%)$ patients. No ND was performed in $115 \mathrm{cN} 0(14.1 \%)$ cases.

\section{Adjuvant treatment}

Based on pathological findings, 95 (11.6\%) patients were subjected to adjuvant treatment. Ninety-four (99.0\%) were subjected to radiotherapy. The indications were: $\mathrm{pN}>1$ (60 patients - 63.8\%) and/or gross extralaryngeal extension (34 patients - 36.2\%) with or without positive margins. A large volume encompassing the primary site and all draining lymph nodes were irradiated with a dose of up to 54 Gy. Regions at higher risk for malignant dissemination received a 12 Gy boost (total, 66 Gy; range, 62-68 Gy). Because of a higher risk of local recurrence [Delphian nodes $\mathrm{pN}+, \mathrm{pN}+$ with extracapsular spread (ECS), more extended pT4a tumours showing positive/ close margins toward pre-laryngeal tissues, perineural invasion, or cartilage invasion], 52/95 (55.3\%) patients received cisplatin $\left(100 \mathrm{mg} / \mathrm{m}^{2}\right.$ on days 1,22 , and 43$)$ concomitant with radiotherapy.

The remaining patient (1.0\%) was subjected to chemotherapy alone, due to presence of distant metastasis.

\section{Statistical methods}

OS, DSS, DFS, FFL, LFS and laryngo-oesophageal dysfunction-free (LEDFS) ${ }^{19}$ survivals were assessed by Kaplan-Meier curves. Log-rank (LR) and Gehan-Bres- 
Table II. Stratification of patients $(N=819)$ according with the clinic-pathological parameters evaluated as possible risk factors for development of recurrences.

\begin{tabular}{|c|c|c|c|}
\hline \multirow{2}{*}{$\begin{array}{l}\text { Clinic-pathological } \\
\text { parameters }\end{array}$} & \multicolumn{2}{|c|}{ Recurrences } & \multirow[t]{2}{*}{ Patients } \\
\hline & Negative & Positive & \\
\hline \multicolumn{4}{|l|}{ Previous treatment } \\
\hline Positive & $119(16.7 \%)$ & $21(19.4 \%)$ & $140(17.1 \%)$ \\
\hline Negative & 592 (83.3\%) & $87(80.6 \%)$ & $679(82.9 \%)$ \\
\hline \multicolumn{4}{|l|}{ Type of surgery } \\
\hline OPHL Type II & $620(87.2 \%)$ & 77 (71.3\%) & $697(85.1 \%)$ \\
\hline OPHL Type III & $91(12.8 \%)$ & $31(28.7 \%)$ & $122(14.9 \%)$ \\
\hline \multicolumn{4}{|l|}{ Tumour site } \\
\hline Supraglottic & $149(21.0 \%)$ & $32(29.6 \%)$ & $181(22.1 \%)$ \\
\hline Glottic & $556(78.2 \%)$ & $73(67.6 \%)$ & $629(76.8 \%)$ \\
\hline Other & $6(0.8 \%)$ & $3(2.8 \%)$ & $9(1.1 \%)$ \\
\hline \multicolumn{4}{|l|}{ pT stage } \\
\hline pT1 & $3(0.4 \%)$ & $2(1.9 \%)$ & $5(0.6 \%)$ \\
\hline pT2 & 217 (30.5\%) & $17(15.7 \%)$ & $234(28.6 \%)$ \\
\hline рT3 & 385 (54.1\%) & $51(47.2 \%)$ & $436(53.2 \%)$ \\
\hline pT4 & 106 (14.9\%) & $38(35.2 \%)$ & $144(17.6 \%)$ \\
\hline \multicolumn{4}{|l|}{ pN stage } \\
\hline pNO & $645(90.7 \%)$ & $76(70.4 \%)$ & $721(88.0 \%)$ \\
\hline pN1 & 30 ( $4.2 \%)$ & $13(12.0 \%)$ & $43(5.3 \%)$ \\
\hline pN2 & 36 ( $5.1 \%)$ & $19(17.6 \%)$ & $55(6.7 \%)$ \\
\hline \multicolumn{4}{|l|}{ Grading } \\
\hline Basaloid & 10 ( $1.4 \%)$ & $3(2.8 \%)$ & $13(1.6 \%)$ \\
\hline G1 & $179(25.2 \%)$ & $11(10.2 \%)$ & $190(23.2 \%)$ \\
\hline G2 & 326 (45.9\%) & $45(41.7 \%)$ & $371(45.3 \%)$ \\
\hline G3 & $196(27.6 \%)$ & $49(45.4 \%)$ & 245 (29.9\%) \\
\hline \multicolumn{4}{|c|}{ Cartilage involvement } \\
\hline Positive & 116 (16.3\%) & $50(46.3 \%)$ & $166(20.3 \%)$ \\
\hline Negative & 595 (83.7\%) & $58(53.7 \%)$ & $653(79.7 \%)$ \\
\hline \multicolumn{4}{|l|}{ Vascular invasion } \\
\hline Positive & $194(27.3 \%)$ & $43(39.8 \%)$ & 237 (28.9\%) \\
\hline Negative & $517(72.7 \%)$ & $65(60.2 \%)$ & $582(71.1 \%)$ \\
\hline \multicolumn{4}{|l|}{ Perineural invasion } \\
\hline Positive & $119(16.7 \%)$ & $39(36.1 \%)$ & $158(19.3 \%)$ \\
\hline Negative & $592(83.3 \%)$ & $69(63.9 \%)$ & $661(80.7 \%)$ \\
\hline \multicolumn{4}{|c|}{ Delphian lymph node pN+ } \\
\hline Positive & 19 ( $2.7 \%)$ & $10(9.3 \%)$ & $29(3.5 \%)$ \\
\hline Negative & $692(97.3 \%)$ & $98(90.7 \%)$ & $790(96.5 \%)$ \\
\hline \multicolumn{4}{|l|}{ Extranodal extension } \\
\hline Positive & $18(2.5 \%)$ & $11(10.2 \%)$ & $29(3.5 \%)$ \\
\hline Negative & $693(97.5 \%)$ & $97(89.8 \%)$ & 790 (96.5\%) \\
\hline \multicolumn{4}{|l|}{ Status of margins } \\
\hline Positive & 55 ( $7.7 \%)$ & $13(12.0 \%)$ & 68 ( $8.3 \%)$ \\
\hline Close & 29 ( $4.1 \%)$ & $14(13.0 \%)$ & $43(5.3 \%)$ \\
\hline Negative & $627(88.2 \%)$ & $81(75.0 \%)$ & 708 (86.4\%) \\
\hline \multicolumn{4}{|l|}{ Adjuvant treatment } \\
\hline Positive & $67(9.4 \%)$ & 28 (25.9\%) & $95(11.6 \%)$ \\
\hline Negative & $644(90.6 \%)$ & $80(74.1 \%)$ & 724 (88.4\%) \\
\hline
\end{tabular}

Table III. Treatments performed in the 819 patients.

\begin{tabular}{|c|c|}
\hline Type of treatment & N (\%) \\
\hline \multicolumn{2}{|l|}{$\mathrm{OPHL}$} \\
\hline Ila & $159(19.4 \%)$ \\
\hline$\| \mathrm{a}+\mathrm{ARY}$ & $354(43.2 \%)$ \\
\hline Ilb & $46(5.6 \%)$ \\
\hline$\| \mathrm{lb}+\mathrm{ARY}$ & $138(16.9 \%)$ \\
\hline Illa & $10(1.2 \%)$ \\
\hline Illa + CAU & $99(12.1 \%)$ \\
\hline Illb & $5(0.6 \%)$ \\
\hline$\| l l b+C A U$ & $8(1.0 \%)$ \\
\hline
\end{tabular}

low-Wilcoxon (GBW, for early events) tests were used to compare Kaplan-Meier estimates among the different subcategories.

The endpoints considered were obtained as the length of time from the date of diagnosis to: date of death (OS), date of death from disease (DSS), date of first recurrence (DFS), date of salvage laryngectomy (FFL), date of salvage total laryngectomy or date of death (LFS), date of salvage total laryngectomy or date of tracheostomy and/ or PEG for functional reasons or date of death (LEDFS). Univariate regression with collinearity analysis was used to evaluate independent risk factors (previous treatment, type of surgery, tumour site, pT stage, pN stage, grading, cartilage involvement, vascular or perineural invasion, Delphian lymph node $\mathrm{pN}+$, ENE, status of margins, and adjuvant treatment). Variables were than included in logistic regression model. Kaplan-Meier curves, LR and GBW tests were performed with GraphPad Prism version 7.0a (GraphPad Software, San Diego, CA, USA), whereas univariate and multivariate regression analyses were performed with IBM ${ }^{\circledR}$ SPSS $^{\circledR}$ Statistics version 24 (IBM Corp., Armonk, NY, USA). The incidences of relevant prognostic factors were analysed by a chi-squared test (PRIMIT-statistics for biomedical learning version 3.03). For all analyses, $\mathrm{p}<0.05$ was considered as the threshold for statistical significance.

\section{Results}

Pathology

Pathology reports showed close margins $(<2 \mathrm{~mm}$ on the specimen side) in 43 cases of 819 (5.3\%) and positive margins (negative at frozen sections on the mucosa taken from the remaining larynx, but positive at definitive histopathologic examination on specimen) in 68 cases $(8.3 \%)$. Positive or closed margins were associated with more advanced $\mathrm{pT}$ classification in both previously treat- 
ed $(\mathrm{p}<0.05)$ and untreated $(\mathrm{p}<0.001)$ patients, while it correlated with the employment of the more aggressive OPHL type III only in previously treated patients $(\mathrm{p}<0.01)$.

We detected 166 patients with cartilage invasion among the $582(28.5 \%)$ who are affected by T3-T4 tumours (categories that could have cartilage invasion as definition). In particular, we detected the following pattern of cartilage invasion: 86/166 (51.8\%) inner cortex of thyroid cartilage, 59/166 (35.5\%) full thickness thyroid cartilage, 13/166 (7.8\%) cricoid cartilage and 8/166 (4.9\%) epiglottis cartilage. Among patients who experienced a recurrence, $50(46.3 \%)$ had pathologic involvement of cartilages, the majority $(44,88.0 \%)$ at level of the thyroid cartilage. Furthermore, the development of recurrences and crico-arytenoid fixation did not correlate with pathological grading of lesions.

Finally, 746/819 patients (91.1\%) had been staged as cN0. In contrast, $44(5.9 \%)$ became pN+ after ND. Overall, lymph node metastases were detected in 98 (11.9\%) patients, of whom 55 (56.1\%) had multiple metastases.

\section{Patterns of failure}

Globally, 108 (13.2\%) patients developed recurrences within 5 years after surgery. Thirty-eight patients (35.2\%) displayed local recurrence, 25 patients $(23.1 \%)$ regional and $8(7.4 \%)$ distant. Twenty $(18.5 \%)$ had local and regional recurrences, $6(5.6 \%)$ were regional and distant and $4(3.7 \%)$ local and distant recurrences. 7 patients $(6.5 \%)$ developed both loco-regional and distant recurrences.

Among the 69 patients affected by local recurrence, 55 were endolaryngeal (79.7\%), 9 extralaryngeal $(13.0 \%)$ and 5 indeterminate $(7.3 \%)$. The regional recurrences were detected on level VI in $19 / 58$ patients (32.8\%), whereas it affected levels II-V in the remaining 39 cases $(67.2 \%)$. Among the latter, $34(87.2 \%)$ recurrences were detected homolaterally, 3 contralaterally $(7.7 \%)$ and 2 bilaterally $(5.1 \%)$.

Recurrences were detected equally in patients who received previous treatments $(21 / 140,15.0 \%)$ or not $(87 / 679,12.8 \%, p=0.576)$. Furthermore, local recurrences displayed similar patterns between the two groups $(\mathrm{p}=0.917)$. Otherwise, although the difference was not statistically significant $(\mathrm{p}=0.065)$, previously treated $\mathrm{pa}-$ tients seemed to have a higher incidence of regional recurrences at level VI $(6 / 10,60.0 \%)$ compared with the other patients $(13 / 48,27.1 \%)$. Furthermore, no differences ( $p=0.241)$ were detected in terms of distant recurrences. Similarly, no differences in terms of regional recurrences were detected between patients who underwent (47/704) or not $(11 / 115, \mathrm{p}=0.356) \mathrm{ND}$. At any rate, among those who also received level VI clearance (20/449), the associated risk was higher $(\mathrm{p}=0.055)$ likely due to a more advanced pathology.

Survival and disease control according to different patterns of failure

Patients were followed for a minimum period of 2 years and a maximum period of 16.4 years. The mean and the median period were 5.3 and 4.8 years, respectively. Eight patients were lost to follow-up: 3 among recurrent patients and 5 not previously treated. 5-year survival estimates are reported in Table IV. All endpoints were highly impaired by the onset of recurrences $(\mathrm{p}<0.001, \mathrm{LR}$ and GBW) compared to the non-recurring counterpart. Even if the majority of stratifications did not indicate significant differences among the different types of local recurrence, OS and DSS were more affected by local recurrences of

Table IV. Five-year Kaplan-Meier estimates of assessed oncologic outcomes.

\begin{tabular}{|c|c|c|c|c|c|c|}
\hline & OS & DSS & DFS & $\mathrm{FFL}$ & LFS & LEDFS \\
\hline \multicolumn{7}{|l|}{ Patients with recurrent tumours } \\
\hline \multicolumn{7}{|l|}{$\mathrm{T}$} \\
\hline Endolaryngeal & $57.8 \%$ & $69.7 \%$ & $7.8 \%$ & $42.5 \%$ & $33.2 \%$ & $16.5 \%$ \\
\hline Extralaryngeal & $64.8 \%$ & $88.9 \%$ & $0.0 \%$ & $38.1 \%$ & $27.8 \%$ & $0.0 \%$ \\
\hline Indeterminate & $28.6 \%$ & $28.6 \%$ & $0.0 \%$ & $47.6 \%$ & $28.6 \%$ & $14.3 \%$ \\
\hline \multicolumn{7}{|l|}{$\mathrm{N}$} \\
\hline Level II-V & $42.5 \%$ & $63.9 \%$ & $5.3 \%$ & $74.8 \%$ & $37.1 \%$ & $25.1 \%$ \\
\hline Level VI & $51.2 \%$ & $63.3 \%$ & $11.1 \%$ & $59.5 \%$ & $41.4 \%$ & $20.8 \%$ \\
\hline \multicolumn{7}{|l|}{ M } \\
\hline Positive & $40.0 \%$ & $43.6 \%$ & $9.5 \%$ & $81.3 \%$ & $33.9 \%$ & $21.8 \%$ \\
\hline Patients with non-recurrent tumours & $93.4 \%$ & $98.9 \%$ & $100 \%$ & $99.8 \%$ & $93.2 \%$ & $93.1 \%$ \\
\hline
\end{tabular}

OS: overall survival; DSS: disease-specific survival; DFS: disease-free survival; FFL: freedom from laryngectomy; LFS: laryngectomy-free survival; LEDFS, laryngo-oesophageal dysfunction-free survival. 
undetermined origin. These were, indeed, more prone to induce the exitus of patients with respect to both intralaryngeal $(p<0.05$, OS, and $p<0.01$, DSS) and clearly extralaryngeal ( $p<0.05$ OS and DSS) recurrences.

Comparing previously treated and untreated patients, there was no significant differences, with the exception of the incidence of recurrence on regional lymph node $(\mathrm{p}<0.01)$. This was likely because previous treatment already involved this site.

\section{Risk analysis on the development of recurrences}

At univariate analysis, all variables assessed correlated $(p<0.05)$ with development of recurrences. Nevertheless, at logistic regression, significantly correlated variables were $\mathrm{pN}$ classification $(\mathrm{p}<0.001)$, presence of cartilage involvement $(p<0.001)$, presence of perineural invasion $(\mathrm{p}<0.05)$ and type of surgical treatment (OPHL type III, $\mathrm{p}<0.05$ ) (Table V).

The onset of recurrences was detected in the $30.6 \%$ of patients diagnosed with $\mathrm{pN}+$ cancers and in $10.5 \%$ of pN0 $(R R=3.1)$. Similarly, the frequencies of recurrence were higher in patients with cartilage invasion, both the inner cortex or through the outer cortex, $(30.1 \%)$ and/or perineural invasions $(24.7 \%)$, compared to those without these aspects $(8.9 \% \mathrm{RR}=3.4$ and $10.4 \% \mathrm{RR}=2.4$, respectively). More extended OPHL type III entailed a $25.4 \%$ of recidivate patients, whereas the onset of recurrence after OPHL type II was limited to $11.0 \%(\mathrm{RR}=2.3)$. At further analysis, OPHL type III was more frequently employed in patients with previous treatment and in glottic tumours (both $\mathrm{p}<0.001$ ), though being responsible for a higher incidence of recurrences at level VI $(\mathrm{p}<0.01)$.

\section{Discussion}

$\mathrm{T}$ and $\mathrm{N}$ staging are recognised as the best factor to predict survival of patients with laryngeal cancer ${ }^{20} 2124$. Notwithstanding, prognosis is generally more complex and also depends on many other variables, such as age, clinicalpathologic characteristics, surgical margin status and type of surgery. Some of these could be responsible of adverse events ${ }^{22}$, complications or even recurrences that hamper survival of patients ${ }^{16}$. Thus, the literature is rich in manuscripts describing demographic, clinical, pathological and therapeutic variables that have been evaluated as possible prognostic factors for local control of disease and overall survival in patients affected by laryngeal cancer.

On the other hand, evaluation of prognostic factors that are expendable in predicting the onset of recurrences are not so common. The data emerging from this analysis do not correspond exactly to the few studies that have performed appropriate statistical assessment on these factors and the possible inter-relationship between them ${ }^{23}$.

Among the few, in the analysis of 253 patients affected glottic and supraglottic laryngeal cancer and undergoing OPHL, Gallo and colleagues ${ }^{20}$ demonstrated that the presence of positive surgical margin was the unique significant prognostic factor correlated with the onset of local recurrences. However, we should keep in mind that this was a monocentric study, homogenous regarding indications and surgical techniques and no patients were included with previous treatment for laryngeal cancer. Indeed, with regards to the major differences found between the study by Gallo and coworkers ${ }^{20}$, focused on the parameters influencing local control and survival after

Table V. Analyses of factors predicting recurrence.

\begin{tabular}{lcccc} 
Variable & \multicolumn{2}{c}{ Univariate analysis } & \multicolumn{2}{c}{ Logistic regression model } \\
& Score test & P value & Score test & P value \\
Previous treatments & 0.604 & 0.437 & 0.038 & 0.846 \\
Type of surgery & 14.118 & $<0.001$ & 4.928 & 0.026 \\
Tumour site & 1.131 & 0.288 & 0.932 & 0.334 \\
pT subcategory & 16.389 & $<0.001$ & 0.100 & 0.752 \\
pN $\geq 1$ staging & 15.742 & $<0.001$ & 15.643 & $<0.001$ \\
Grading & 6.481 & 0.011 & 1.299 & 0.254 \\
Cartilage involvement & 38.174 & $<0.001$ & 24.221 & $<0.001$ \\
Vascular invasion & 3.725 & 0.054 & 0.857 & 0.355 \\
Perineural invasion & 15.062 & $<0.001$ & 6.018 & 0.014 \\
Delphian node pN+ & 5.033 & 0.025 & 0.155 & 0.694 \\
Extranodal extension & 16.620 & $<0.001$ & 2.253 & 0.133 \\
Status of margins & 6.124 & 0.013 & 1.253 & 0.263 \\
Adjuvant treatments & 14.393 & $<0.001$ & 0.859 & 0.354 \\
\hline
\end{tabular}


supracricoid laryngectomy, it should be noted that neither $\mathrm{T}$ category nor positivity of resection margins correlated with the risk of recurrence.

The reason may lie in the different types of surgery adopted. In addition, in order to point out the factors that underlie the onset of recurrences $(\mathrm{n}=108,13.2 \%)$ in a broader cohort of patients $(n=819)$, we analysed oncologic results. To obtain this, we subdivided patients accordingly to their pattern of failure. All oncologic outcomes (OS, DSS, DFS, FFL, LFS, and LEDFS) were significantly impaired by the onset of recurrences though the entity was similar among the different pattern on T, N and M. However, local recurrences $(\mathrm{T})$ of indeterminate origin, meaning an iceberg-like recurrence affecting in small part the remnant endolarynx, but massively the paralaryngeal tissues, were more prone to induce exitus (OS and DSS) of patients with respect to the intralaryngeal and extralaryngeal ones. In fact, in these cases it is practically impossible to carry out salvage resection in free and safe margins because diagnosis of recurrence was often late.

Considering that, as expected, recurrent patients had worse prognosis than non-recurrent ones, we evaluated the characteristics of the two populations to detect possible risk factors. Among the 13 different variables assessed, at logistic regression analysis only $\mathrm{pN} \geq 1$, cartilage invasion (both the inner cortex or through the outer cortex), perineural invasion and employment of more invasive OPHL type III were directly correlated with the onset of recurrences.

$\mathrm{N}$ classification has been often related to worse prognosis. In this point of view, it should not be surprising that patients classified as $\mathrm{pN} \geq 1$ had a higher risk $(\mathrm{RR}=3.1)$ to generally develop recurrences than those without lymph node involvement ( $\mathrm{pN} 0$ ). Neck dissection was performed with either elective or curative purposes in the majority of patients (85.9\%). Nevertheless, neck recurrences were detected in 25 of $98(25.5 \%) \mathrm{pN}+$ patients, of whom 14 $(14.3 \%)$ had undergone adjuvant radiotherapy or radiochemotherapy, and in 33 of 721 (4.6\%) pN0 patients. Interestingly, recurrences were predominantly at levels II-V in $\mathrm{pN}+$ patients $(88.0 \%)$, but were equally detected at both level VI (48.5\%) and levels II-V (51.5\%) in pN0 patients. This different distribution was likely due to the cancer localisation, as recurrence at levels II-V are more frequent in supraglottic tumours. In fact, lymph node relapsing patients were affected by supraglottic cancer in $56.0 \%$ of $\mathrm{pN}+$ cases, if compared with the $24.2 \%$ of those $\mathrm{pN} 0$ $(\mathrm{p}<0.05)$. Nevertheless, no differences in terms of tumour classification or use of adjuvant therapy were detected between relapsing and non-relapsing $\mathrm{pN}+$ patients.

In the present cohort, patients with cartilage invasion at the inner cortex or through the outer cortex showed a greater probability to develop recurrences $(\mathrm{RR}=3.4)$. This phenomenon is because the cartilage invasion demonstrates an extralaryngeal escape pathway. This aspect, if suspected pre-operatively, should always determine the recourse to a ND of the ipsilateral levels II-IV, but in particular to meticulous dissection of the central compartment of the neck as well as strap muscles resection and dissection of the pre-laryngeal tissue, immediately analysed by frozen sections. Considering the pattern of failure, the involvement of cartilages had no effect on $\mathrm{T}$ and $\mathrm{M}$ recurrence, but significantly correlated with that on N. Indeed, cartilage invasion increased the rate of recurrences on level VI lymph nodes $(14 / 50,28.0 \%, \mathrm{p}<0.05)$ rather than level II-V ones $(10 / 50,20.0 \%, \mathrm{p}<0.01)$, compared to patients with negative cartilage $(5 / 58,8.6 \%$; and $29 / 58,50.0 \%$, respectively). The lack of significance at logistic regression of $\mathrm{T}$ classification, despite being strongly related to depth of cartilage invasion seems plausible to us because, beyond T4 tumours, many lesions classified as T3 had focal or multifocal invasion of internal lamina of thyroid cartilage. This phenomenon occurs more frequently in the lower aspect of the thyroid cartilage since the tumour often shows progression towards the crico-thyroid space. Even in the absence of full-thickness cartilage invasion, the behaviour of this subcategory of tumours, schematically represented by a subglottic extension more than $10 \mathrm{~mm}$ at the true vocal cord (TVC) midline, is to be considered similar to that of tumours staged in the upper category of T4a. Therefore, more cautious surgical resection should be preferred, characterised by careful dissection of level VI nodes.

For what concerns perineural invasion, although enhancing the overall risk of developing recurrences $(R R=2.4)$, the risk factor did not correlate per se with significant alteration of the pattern of failure. However, it is generally present in tumours characterised by advanced $\mathrm{T}$ stage and high histological grade classification, which are thus more refractory to treatments and show worse prognosis. Patients with perineural invasion should undergo strict follow-up to diagnose recurrences early. Moreover, this result gives rise to discussions in the tumour board about the necessity to treat patients affected by locally advanced tumours with adjuvant radiotherapy, possibly showing this negative prognostic factor for loco-regional recurrence.

Finally, regarding the type of surgery, we detected a higher risk of developing recurrences in cases treated by OPHL type III $(\mathrm{RR}=2.3)$. We should keep in mind that supratracheal laryngectomies (OPHL type III) are generally employed in the treatment of more aggressive and advanced disease. Thus, more attention should be paid to this analysis. 
Undoubtedly, OPHL type III extended indications of partial laryngectomy in case of cancers (glottic-subglottic tumours, T4a tumours) that, historically, were treated by total laryngectomy. Nevertheless, it determines a major rate of close margins, negative the frozen sections when the sample is collected on the side of the remnant larynx, but positive on the side of the specimen, generally correlates with a major rate of level VI lymph nodes metastasis. Although not mathematically, considering that the larynx also "accepts" minimal resection margins, this can expose patients to a greater number of loco-regional relapses (compared to those after OPHL type II) especially when detected as $\mathrm{T}$ indeterminate feature recurrences or on the level VI lymph nodes. Therefore, cases to be addressed to this surgical option must be selected very well.

OPHLs type III are safely indicated in case of T3 tumours with subglottic extension preferable $<10 \mathrm{~mm}$ at the TVC midline or in case of T4a "anterior" tumour ${ }^{15}$, because these patients have demonstrated good oncologic results with a low percentage of recurrence. On the contrary, even $\mathrm{T} 3$ or T4a "posterior" tumours, where arytenoid fixity is related to an infraglottic extension $>10 \mathrm{~mm}$ at the TVC midline or to a massive posterior crico-arytenoid unit invasion, the tumour clearly acts aggressively as if it were always a $\mathrm{T} 4$.

OPHLs type III surgeries are therefore quite safe in first two cases, especially if the resection encompasses one crico-arytenoid unit. In the latter conditions, the safest treatment is total laryngectomy, also considering some disappointing events (positive margins, level VI pN+, ENE), that are more frequently associated with recurrence. Only in the case of categorical refusal by the patient to total laryngectomy, after informing about the risk of giving priority to the functional outcomes rather than to oncologic ones, in some very selected cases it is still possible to carry out an OPHL type IIIa. This option, even if not optimal, should be equally considered as chemoradiotherapy when drafting guidelines.

\section{Conclusions}

To our knowledge, this study is the first to use logistic regression on a very large cohort of patients treated by all different types of supracricoid and supratracheal partial laryngectomies (OPHL type II / III). The detection of clinical and pathological parameters that correlate with the development of recurrences ( $\mathrm{pN}$ classification, cartilage involvement, perineural invasion, and thus the type of surgical treatment adopted) can be useful to reduce the event rate. Therefore, we suggest serious discussion in the multidisciplinary tumour board regarding the possible in- dications of OPHL, rather than resorting to a simpler and safer total laryngectomy or, alternatively, to concomitant chemoradiation-therapy, especially in cases where additional risk factors are present, such as the exiguity of surgical margins and use of more extensive surgeries.

In this delicate process, the patient and his/her caregivers also are involved, being important actors. With due delicacy, also analysing data from large series, they must be faced with and helped in choosing among the difficult dichotomy to give greater emphasis to a "quoad vitam" rather than to a "quoad functionem" prognosis.

\section{Acknowledgements}

This paper was awarded with the first prize of the Italian Society of Otorhinolaryngology, Head and Neck Surgery, Caliceti - Citelli - Pietrantoni at the $105^{\text {th }}$ SIOeChCF National Meeting, Napoli May 16-19, 2018. These researches have been supported by "FPRC 5xmille Ministero Salute 2016 (Progetto "Approccio di ricerca diagnostico e terapeutico al paziente con Tumori del Colon Retto del distretto cervico-facciale ARIDTE-Biohenec).

\section{Conflict of interest statement}

None declared.

\section{References}

1 Succo G, Bussi M, Presutti L, et al. Supratracheal laryngectomy: current indications and contraindications. Acta Otorhinolaryngol Ital 2015;35:146-56.

2 Bernier J, Domenge C, Ozsahin M, et al. European Organization for Research and Treatment of Cancer Trial 22931. Postoperative irradiation with or without concomitant chemotherapy for locally advanced head and neck cancer. N Engl J Med 2004;350:1945-52. https://doi.org/10.1056/NEJMoa032641.

3 Succo G, Crosetti E, Bertolin A, et al. Benefits and drawbacks of open partial horizontal laryngectomies, Part A: early- to intermediate-stage glottic carcinoma. Head Neck 2016;38(Suppl 1):E333-40. https://doi.org/10.1002/hed.23997.

4 Peretti G, Piazza C, Mensi M, et al. Endoscopic treatment of cT2 glottic carcinoma: prognostic impact of different $p T$ subcategories. Ann Otol Rhinol Laryngol 2005;114:579-86. https://doi. org/10.1177/00034894051140080.

5 Succo G, Crosetti E, Bertolin A, et al. Benefits and drawbacks of open partial horizontal laryngectomies, Part B: intermediate and selected advanced stage laryngeal carcinoma. Head Neck 2016;38 (Suppl.1):E649-57. https://doi.org/10.1002/hed.24064.

6 Tomeh C, Holsinger FC. Laryngeal cancer. Curr Opin Otolaryngol Head Neck Surg 2014;22:147-53. https://doi.org/10.1097/ MOO.0000000000000032.

7 Forastiere AA, Zhang Q, Weber RS, et al. Long-term results of RTOG 91-11: a comparison of three nonsurgical treatment strategies to preserve the larynx in patients with locally advanced larynx cancer. J Clin Oncol 2013;31:845-52. https://doi.org/10.1200/ JCO.2012.43.6097. 
8 Olsen K. Reexamining the treatment of advanced laryngeal cancer. Head Neck 2010:32:1-7. https://doi.org/10.1002/hed.21294.

9 Benito J, Holsinger FC, Perez-Martin A, et al. Aspiration after supracricoid partial laryngectomy: incidence, risk factors, management, and outcomes. Head Neck 2011;33:679-85. https://doi. org/10.1002/hed.21521.

10 Sobin LH, Gospodarowicz MK, Wittekind C. TNM classification of malignant tumours. $7^{\text {th }}$ edition. Hoboken, NJ: Wiley-Blackwell; 2011.

11 Karnofsky D, Burchenal J. The clinical evaluation of chemotherapeutic agents in cancer. In: MacLeod CM, editor. Evaluation of Chemotherapeutic agents. New York: Columbia University Press; 1949. pp. 191-205.

12 Pinar E, Imre A, Calli C, et al. Supracricoid partial laryngectomy: analyses of oncologic and functional outcomes. Otolaryngol Head Neck Surg 2012:147:1093-8. https://doi. org/10.1177/0194599812457334.

13 Rizzotto G, Crosetti E, Lucioni M, et al. Oncological outcomes of supratracheal laryngectomy: a critical analysis. Head Neck 2015;37:1417-24. https://doi.org/10.1002/hed.23773.

14 Rizzotto G, Crosetti E, Lucioni M, et al. Subtotal laryngectomy: outcomes of 469 patients and proposal of a comprehensive and simplified classification of surgical procedures. Eur Arch Otorhinolaryngol 2012;269:1635-46. https://doi.org/10.1007/s00405-012-1928-4.

15 Succo G, Crosetti E, Bertolin A, et al. Treatment of T3-T4a laryngeal cancer by open partial horizontal laryngectomies: prognostic impact of different pT subcategories. Head Neck 2018;40:1897-908. https://doi.org/10.1002/hed.25176.

16 Crosetti E, Caracciolo A, Molteni G, et al. Unravelling the risk factors that underlie laryngeal surgery in elderly. Acta Otorhinolaryngol Ital 2016:36:185-93. https://doi.org/10.14639/0392-100X-817.

17 Succo G, Peretti G, Piazza C, et al. Open partial horizontal lar- yngectomies: a proposal for classification by the working committee on nomenclature of the European Laryngological Society. Eur Arch Otorhinolaryngol 2014;271:2489-96. https://doi.org/10.1007/ s00405-014-3024-4.

18 Robbins KT, Medina JE, Wolfe GT, et al. Standardizing neck dissection terminology. Official report of the Academy's Committee for Head and Neck Surgery and Oncology. Arch Otolaryngol Head Neck Surg 1991;117:601-5.

19 Ang K. Larynx preservation clinical trial design: summary of key recommendations of a consensus panel. Oncologist 2010;15(Suppl 3):25-9. https://doi.org/10.1634/theoncologist.2010-S3-25.

20 Gallo A, Manciocco V, Simonelli M, et al. Supracricoid partial laryngectomy in the treatment of laryngeal cancer: univariate and multivariate analysis of prognostic factors. Arch Otolaryngol Head Neck Surg 2005:131:620-5. https://doi.org/10.1001/archotol.131.7.620.

21 LeBlanc B, Shi R, Mehta V, et al. Improvements in survival and disparities for advanced-stage laryngeal cancer. JAMA Otolaryngol Head Neck Surg 2015:141:169-73. https://doi.org/10.1001/jamaoto.2014.2998.

22 Pezier T, Nixon I, Joshi A, et al. Pre-operative tracheostomy does not impact on stomal recurrence and overall survival in patients undergoing primary laryngectomy. Eur Arch Otorhinolaryngol 2013;270:1729-35. https://doi.org/10.1007/s00405-012-2213-2.

23 Joo YH, Park JO, Cho KJ KM. Relationship between paraglottic space invasion and cervical lymph node metastasis in patients undergoing supracricoid partial laryngectomy. Head Neck 2012:34:1119-22. https://doi.org/10.1002/hed.21892.

24 Atallah I, Berta E, Coffre A, et al. Supracricoid partial laryngectomy with crico-hyoido-epiglottopexy for glottic carcinoma with anterior commissure involvement. Acta Otorhinolaryngol Ital 2017;37:18894. https://doi.org/10.14639/0392-100X-1002.

Received: November 1, 2018 - Accepted: January 11, 2019

How to cite this article: Crosetti E, Bertolin A, Molteni G, et al. Patterns of recurrence after open partial horizontal laryngectomy types II and III: univariate and logistic regression analysis of risk factors. Acta Otorhinolaryngol Ital 2019;39:235-243. https://doi. org/10.14639/0392-100X-2409

Address for correspondence: Erika Crosetti, Head and Neck Oncology Service, FPO IRCCS, Candiolo Cancer Institute, Candiolo (TO), Italy. Tel. +39011 9933663. E-mail: erika.crosetti@ircc.it 